\title{
Monitoring Spruce Budworm with Light Traps: The Effect of Trap Position
}

\author{
Marc Rhainds and Edward G. Kettela \\ Natural Resources Canada, Canadian Forest Service-Atlantic Forestry Centre, P.O. Box 4000, Fredericton, NB, Canada E3B 5P7 \\ Correspondence should be addressed to Marc Rhainds; mrhainds@nrcan.gc.ca
}

Received 1 June 2014; Revised 19 August 2014; Accepted 25 September 2014; Published 4 November 2014

Academic Editor: Russell Jurenka

Copyright (C) 2014 M. Rhainds and E. G. Kettela. This is an open access article distributed under the Creative Commons Attribution License, which permits unrestricted use, distribution, and reproduction in any medium, provided the original work is properly cited.

\begin{abstract}
Daily records of adult spruce budworms, Choristoneura fumiferana (Clemens) (Lepidoptera: Tortricidae), captured at light traps at multiple locations in New Brunswick in the 1970s, are analyzed in relation to the physical position of light traps (tree canopies or forest clearings). Captures at light traps deployed in tree canopies were 4-400 times greater than those in forest clearings, especially for males. The phenology of captures (median date or duration of flight period) did not differ in relation to trap location. Captures of both males and females in tree canopies were highly correlated with egg densities, whereas no significant relationship was observed for either sex in forest clearings. Monitoring programs for spruce budworm adults using light traps should be standardized by deploying traps in tree canopies.
\end{abstract}

\section{Introduction}

The spruce budworm (SBW), Choristoneura fumiferana (Clemens) (Lepidoptera: Tortricidae), is the most severe defoliator of conifers in the Nearctic boreal forest [1,2]. Population dynamics of SBW are strongly influenced by longrange migration of adults that ascend to the atmospheric boundary layer to be carried downwind [3]. Understanding dispersal-migration in SBW is important to forecast the spatiotemporal occurrence of outbreaks and implement sound pest management strategies $[4,5]$.

In the 1980s, monitoring procedures to assess the abundance of adult SBW shifted from light traps $[6,7]$ to traps baited with female sex pheromone [8]. Captures of SBW at light traps are sensitive to yearly variations in population density $[9,10]$ and useful for detecting mass-immigration events $[11,12]$. The shortcoming of light traps is that multiple species are attracted, requiring a time-consuming process to sort SBW from other moths. This explains the replacement of light traps by pheromone traps, which are selective in capturing only SBW. During the transition between monitoring procedures, no comparison was made between captures at light traps and pheromone traps; thus, it is not possible to assess the relative performance of these two approaches.
One important difference between light traps and pheromone traps is that the former capture both males and females, whereas the latter capture only males. Strict reliance on pheromone trapping of males may yield inconsistent predictions relative to larval abundance or defoliation intensity because damage is ultimately caused by egg-carrying females and not mate-seeking males [13]. An implicit yet rarely tested assumption underlying monitoring populations with pheromone traps is that the spatiotemporal distributions of mate-seeking males mirror those of ovipositing females; this assumption is probably not valid in SBW due to sex differences in dispersal behavior [3]. These considerations may explain apparent limitations of pheromone trapping as a monitoring tool, for example, poor estimates of larval densities or future defoliation (low $r^{2}$ values of regression models) $[14,15]$, and yearly variation in the relationship between trap captures and larval density [16].

With the looming SBW outbreak soon expected to rage across Atlantic Canada [17], monitoring of adults in future research programs will include an extensive network of both light traps and pheromone-baited traps [http://www.healthyforestpartnership.ca/research-in-action/research-programoverview; accessed 18 August 2014]. One important issue 
to settle before implementing broad-scale light trapping of SBW is standardization of the physical position of light traps in forest habitats. In the past, light traps have been indiscriminately deployed in tree canopies or forest clearings without recording the position of traps $[6,7]$.

Empirical data sources collected in New Brunswick in the 1970s and replicated across multiple locations are summarized here, with the objective of comparing the abundance, sex ratio, and phenology of adult SBW captured at light traps deployed in forest clearings and tree canopies.

\section{Materials and Methods}

The experiment was conducted at four sites in New Brunswick, Canada: Acadia Forest Experiment Station near Fredericton in 1972 and 1976; Chipman in 1973, 1974, and 1975; Juniper in 1975; and Saint-Quentin in 1977 (see [18] for geographic location of sites). The sites consisted of forest stands containing hosts of SBW (balsam fir, Abies balsamea (L.) Mill., and spruces, Picea spp.) as either dominant or codominant tree species.

The light source used to attract moths consisted of a Coleman lantern powered by naphtha gas and operated from sunset until dawn, placed at the center of two crossing vanes that deflected the moths down toward a funnel into the trap; a strip of insecticide (Vapona) was placed at the bottom of the trap to kill captured insects [6]. At each site, one light trap was suspended in the upper canopy of host trees $(>6 \mathrm{~m}$ high) and the other was deployed $2 \mathrm{~m}$ above ground from a tripod in a forest clearing; the distance between edges of forest clearings and traps in tree canopies was $>50 \mathrm{~m}$ at all sites. The traps were inspected daily, and the captured SBW moths were collected to determine abundance of males and females. The same design was used in Saint-Quentin, except that light traps were deployed at nine plots spaced 3-4 km apart along a logging road [19].

Egg density was estimated on the most prevalent host trees of SBW at different sites by pruning one branch (usually $<1 \mathrm{~m}$ long) in the midcanopy of three to five codominant trees and estimating the number of egg masses visually; the surface area of branches was estimated (length $\times$ width of midpoint branch section) and the density of eggs was expressed in terms of egg masses per $10 \mathrm{~m}^{2}$ branch area [2].

Statistical analyses were conducted with the SAS package (SAS Institute, Cary, NC). Three parameters related to phenology were calculated for each site and trap location: (1) the median date of captures; (2) the duration of flight (interval in days between the 5 th and 95th cumulative captures dates); and (3) the proportion of individuals captured at light traps during the modal date of abundance. The cumulative abundance, sex ratio, and phenology of SBW were compared in relation to trap position at different sites using paired $t$ tests; at Saint-Quentin, pooled values across plots were used in analysis.

The relationship between cumulative captures of males and females and the density of eggs per $10 \mathrm{~m}^{2}$ of foliage at different sites was evaluated in relation to sex and trap position using regressions. In addition to the seven aforementioned sites, the regression models also included two sites sampled in 1978 (Saint-Quentin and Amherst, Nova Scotia) for which the cumulative (but not daily) abundance of SBW males and females at light traps was available; therefore, the regression models each included nine data points.

Data were subjected to logarithmic (abundance data) and arcsine (proportion data) transformation to reduce heterogeneity of variance.

\section{Results}

Daily numbers of males and females at TC and FC are plotted for different locations in Figure 1. Captures of adults at TC were 4-400 greater than those at FC (Table 1). The sex ratio of moths at TC was strongly biased toward males, whereas the sex ratio at FC was approximately even. Neither the median date of flight nor the duration of the flight period varied significantly with trap position (Table 1). The proportion of adults captured during the modal date of flight was two times higher at FC than TC (Table 1).

The density of eggs at different sites varied from 36 to 992 egg masses per $10 \mathrm{~m}^{2}$ of foliage. Numbers of males and females captured at TC were positively correlated with the density of eggs, whereas no significant relationship was observed at FC (Figure 2).

\section{Discussion}

With the imminent SBW outbreak in Atlantic Canada, it is important to consolidate and disseminate the information gathered by research scientists during previous outbreaks, in particular as-yet unpublished data. Results obtained through this study are published for the first time and provide a detailed record of daily captures of male and female SBW at light traps deployed in forest clearings or tree canopies at multiple locations. The findings have important implications for the design of monitoring procedures and analysis of time-series data and also provide insight into the dispersalmigration behavior of SBW.

The physical position of light traps must be standardized in monitoring procedures for SBW. Deployment of traps in forest clearings should be avoided due to the low numeric abundance of SBW and the insignificant relationship between moth abundance and egg densities (Table 1, Figure 2). Captures of SBW at light traps in tree canopies, in contrast, provide accurate estimates of egg densities (Figure 2). The relationships were similar for males and females; thus, the time-consuming process of sexing SBW could be omitted in operational programs that are purely management oriented. From a research perspective, recording the sex ratio of moth captures is useful to unravel the role of dispersal-migration on SBW population dynamics. Ideally, both light traps and pheromone-baited traps should be emptied daily or at short intervals to reduce the risk of trap saturation and gain information related to flight phenology and immigration events (nightly captures are characterized by high numerical abundance, predominantly females) $[3,9,11,12]$. 

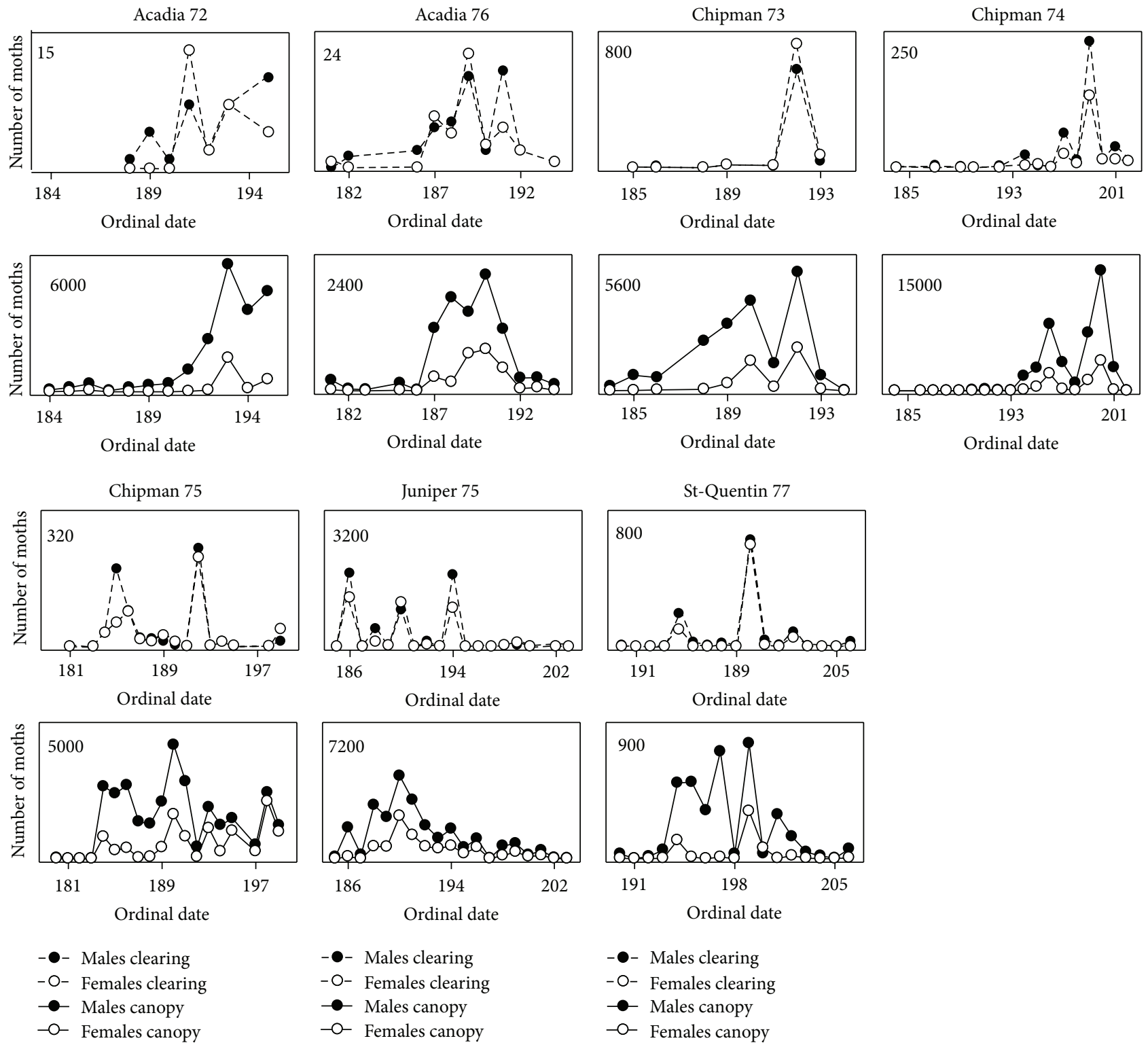

- Males clearing

- O- Females clearing

- Males canopy

- - Females canopy

FIGURE 1: Daily abundance of adult spruce budworms captured at light traps deployed in tree canopies and forest clearings at different sites in New Brunswick, Canada. The numerical values within individual graphs represent the scale of the $y$-axis for different locations and trap position.

TABLE 1: Descriptive parameters related to captures of adult spruce budworms at light traps deployed in tree canopies and forest clearings at seven locations-years (mean $\pm \mathrm{SE}$ ). For each parameter, values with different superscripts are significantly different (paired $t$-tests, $P<0.05$ ). Data were subjected to logarithmic (number of moths) and arcsine (proportional data) transformations to reduce heterogeneity of variance.

\begin{tabular}{|c|c|c|c|c|}
\hline \multirow{2}{*}{ Independent variable } & \multicolumn{2}{|c|}{ Position of traps } & \multicolumn{2}{|c|}{$t$-test } \\
\hline & Tree canopy & Forest clearing & $t$ & $P$ \\
\hline Abundance of moths (1000) & $24.5 \pm 5.6^{\mathrm{a}}$ & $1.9 \pm 1.1^{\mathrm{b}}$ & 5.02 & 0.0024 \\
\hline Sex ratio $\left(P_{\text {females }}\right)$ & $0.193 \pm 0.02^{\mathrm{a}}$ & $0.444 \pm 0.024^{\mathrm{b}}$ & 7.51 & 0.0003 \\
\hline Median date of flight & $192.4 \pm 1.5^{\mathrm{a}}$ & $192.7 \pm 1.6^{\mathrm{a}}$ & 0.26 & 0.8041 \\
\hline Duration of flight (day) & $8.7 \pm 1.3^{\mathrm{a}}$ & $7.2 \pm 1.1^{\mathrm{a}}$ & 1.20 & 0.2741 \\
\hline Proportion of adults (modal date) & $0.251 \pm 0.026^{\mathrm{a}}$ & $0.514 \pm 0.077^{\mathrm{b}}$ & 3.71 & 0.0100 \\
\hline
\end{tabular}



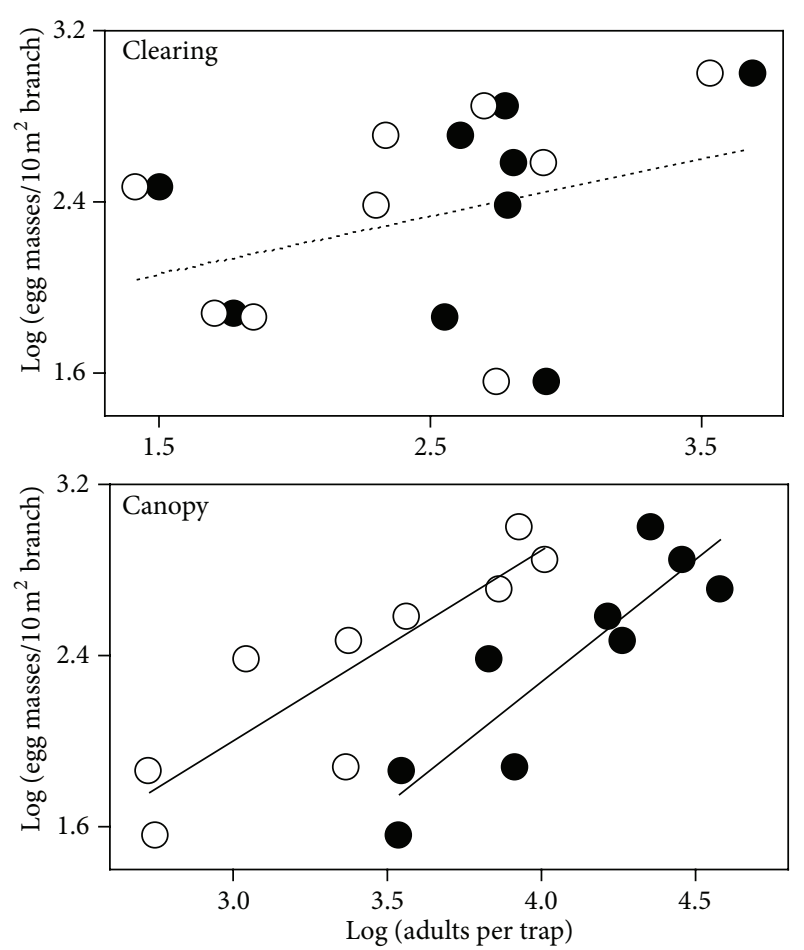

Males
Females

FIGURE 2: Relationships between numbers of adult spruce budworms captured at light traps deployed in tree canopies and forest clearings ( $x$-axis) and the density of eggs ( $y$-axis) at nine locations in New Brunswick, Canada, in the 1970s. Regressions based on captures in tree canopies were statistically significant for both males $\left(y=1.14 x-2.30, r^{2}=0.796\right.$, and $\left.P=0.0012\right)$ and females $\left(y=0.89 x-0.67, r^{2}=0.776\right.$, and $\left.P=0.0017\right)$ (solid lines). Regressions based on captures in forest clearings were not significant for either sex (males: $y=0.27 x+1.67, r^{2}=0.119$, and $P=0.3626$; females: $y=0.34 x+1.56, r^{2}=0.205$, and $P=0.221$ ) (dotted lines). Data were subjected to logarithmic transformations to reduce heterogeneity of variance.

Daily records of moth captures at light traps were kept for multiple locations in Atlantic Canada and Maine in the 1970s $[6,7]$, which might in theory provide extensive timeseries analysis of moth abundance. These data should not be analyzed in this context, however, because the position of traps is unspecified for most sites; thus, sampling artefacts (captures are 4-400 times greater in tree canopies than forest clearings) would systematically bias the outcome of analyses. The data are apparently suitable for evaluating broad-scale trends related to the phenology of flight in SBW, because neither the median date nor the duration of flight periods is influenced by the position of traps (Table 1). Existing phenology models of SBW adult flight need to be validated and calibrated with field data because they do not appear to accurately reflect the timing of SBW flight (Figure 6 in [20]).

It has been hypothesized that light traps deployed in forest clearings capture predominantly dispersive SBW, whereas traps deployed in tree canopies capture local moths [3, 9, $10,12]$. Although this hypothesis cannot be unambiguously tested (because no genotypic-phenotypic traits are available to distinguish migrant from resident adults), its framework can be used to make a priori predictions related to patterns of captures of SBW in traps deployed in tree canopies and forest clearings, specifically: (1) greater captures in tree canopies than forest clearings (due to the greater number of resident moths than dispersers in forest stands with high densities of SBW); (2) greater proportion of females in forest clearings than tree canopies (because females are more likely to disperse than males); (3) shorter durations of moth activity in forest clearings than tree canopies (due to the transient nature of dispersal events relative to patterns of emergenceactivity of resident moths); and (4) greater proportion of moths captured during the modal (peak) date of captures for forest clearings than tree canopies (transience of dispersal events). The data provided strong statistical support for three of the four predictions (Table 1), suggesting that light traps in forest clearings are indeed more likely to capture dispersive SBW than light traps in tree canopies.

\section{Conflict of Interests}

The authors declare that there is no conflict of interests regarding the publication of this paper.

\section{Acknowledgments}

The authors express their gratitude to A. W. Thomas who was responsible for the collection of data and generously granted them the permission to publish them. C. Simpson, V. Martel, and one anonymous reviewer provided useful comments on earlier versions of the paper.

\section{References}

[1] R. F. Morris, The Dynamics of Epidemic Spruce Budworm Populations, vol. 31 of Memoirs of the Entomological Society of Canada, Entomological Society of Canada, 1963.

[2] T. Royama, W. E. MacKinnon, E. G. Kettela, N. E. Carter, and L. K. Hartling, "Analysis of spruce budworm outbreak cycles in New Brunswick, Canada, since 1952," Ecology, vol. 86, no. 5, pp. 1212-1224, 2005.

[3] D. O. Greenbank, W. Schaefer, and R. C. Rainey, "Spruce budworm (Lepidoptera: Tortricidae) moth flight and dispersal: new understanding from canopy observations, radar, and aircraft," Memoirs of the Entomological Society of Canada, vol. 110, pp. 149, 1980.

[4] J. Régnière, J. Delisle, E. Bauce et al., "Understanding of spruce budworm population dynamics: development of early intervention strategies," in Proceedings of the North American Forest Insect Work Conference, Information Report NOR-X-381, pp. 57-68, Edmonton, Canada, 2001.

[5] M. Rhainds, E. G. Kettela, and P. J. Silk, "Thirty-five years of pheromone-based mating disruption studies with Choristoneura fumiferana (Clemens) (Lepidoptera: Tortricidae)," The Canadian Entomologist, vol. 144, no. 3, pp. 379-395, 2012.

[6] J. E. Hurley and F. A. Titus, "Summary of light trap catches for the Maritimes 1976-1986," Information Report M-X-163, 
Natural Resources Canada, Canadian Forest Service-Atlantic Forestry Centre, Fredericton, Canada, 1987.

[7] D. Weed, Spruce Budworm in Maine, 1910-1976: Infestations and Control, Maine Department of Conservation, Maine Forest Service, 1977.

[8] P. J. Silk and L. P. S. Kuenen, "Sex pheromones and behavioral biology of the coniferophagous Choristoneura," Annual Review of Entomology, vol. 33, pp. 83-101, 1988.

[9] C. A. Miller and G. A. McDougall, "Spruce budworm moth trapping data using virgin females," Canadian Journal of Zoology, vol. 51, no. 8, pp. 853-858, 1973.

[10] G. A. Simmons and N. C. Elliott, "Use of moths caught in light traps for predicting outbreaks of the spruce budworm (Lepidoptera: Tortricidae) in Maine," Journal of Economic Entomology, vol. 78, no. 2, pp. 362-365, 1985.

[11] D. O. Greenbank, "The role of climate and dispersal in the initiation of outbreaks of the spruce budworm in New Brunswick. II. The role of dispersal," Canadian Journal of Zoology, vol. 35, no. 3, pp. 385-403, 1957.

[12] R. B. B. Dickison, M. J. Haggis, and R. C. Rainey, "Spruce budworm moth flight and storms: case study of a cold front system," Journal of Climate \& Applied Meteorology, vol. 22, no. 2, pp. 278-286, 1983.

[13] J. N. McNeil, "Behavioral ecology of pheromone-mediated communication in moths and its importance in the use of pheromone traps," Annual Rreview of Entomology, vol. 36, pp. 407-430, 1991.

[14] D. C. Allen, L. P. Abrahamson, D. A. Eggen, G. N. Lanier, S. R. Swier, and R. Kelly, "Monitoring of spruce budworm (Lepidoptera: Tortricidae) populations with pheromone-baited traps," Environmental Entomology, vol. 15, no. 1, pp. 152-165, 1986.

[15] K. Knowles, "Pheromone trapping of adult spruce budworm in the Manitoba Model Forest," 1997, http://www.manitobamodelforest.net/publications/Pheremone\%20Trapping\%20of\%20 Spruce\%20Budworm\%20in\%20MBMF\%2096-3-07.pdf.

[16] C. J. Sanders, "Monitoring spruce budworm population density with sex pheromone traps," The Canadian Entomologist, vol. 120, no. 2, pp. 175-183, 1988.

[17] R. C. Johns and D. Pureswaran, "The pending storm-eastern Canadian foresters brace for spruce budworm," Canadian Forest Industries Magazine, pp. 14-16, 2013.

[18] M. Rhainds, "Field assessment of female mating success based on the presence-absence of spermatophore: a case study with spruce budworm, Choristoneura fumiferana," Annales Zoologici Fennici, vol. 50, no. 6, pp. 377-384, 2013.

[19] M. Rhainds and E. G. Kettela, "Oviposition threshold for flight in an inter-reproductive migrant moth," Journal of Insect Behavior, vol. 26, no. 6, pp. 850-859, 2013.

[20] J. Régnière, R. St-Amant, and P. Duval, "Predicting insect distributions under climate change from physiological responses: spruce budworm as an example," Biological Invasions, vol. 14, no. 8, pp. 1571-1586, 2012. 

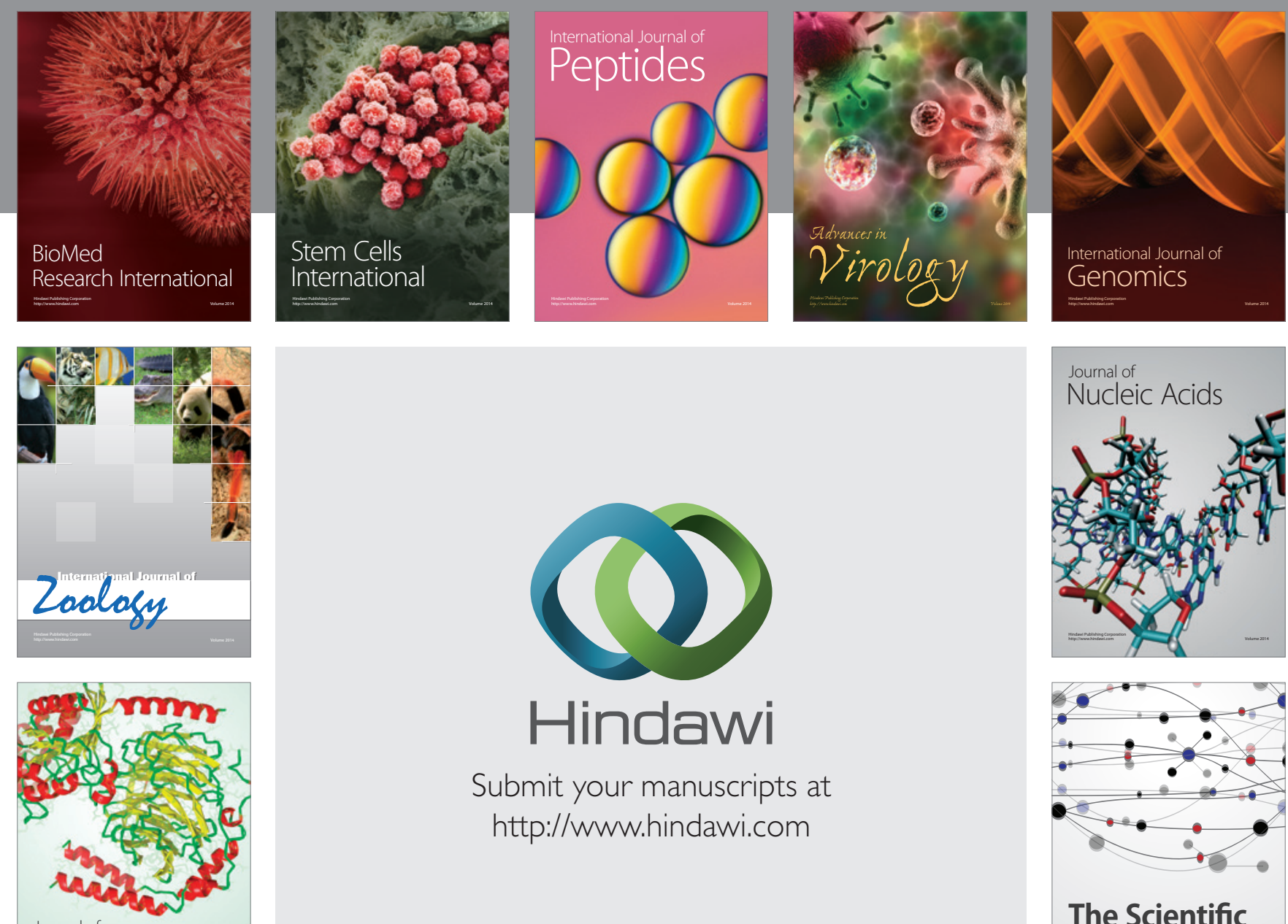

Submit your manuscripts at

http://www.hindawi.com

Journal of
Signal Transduction
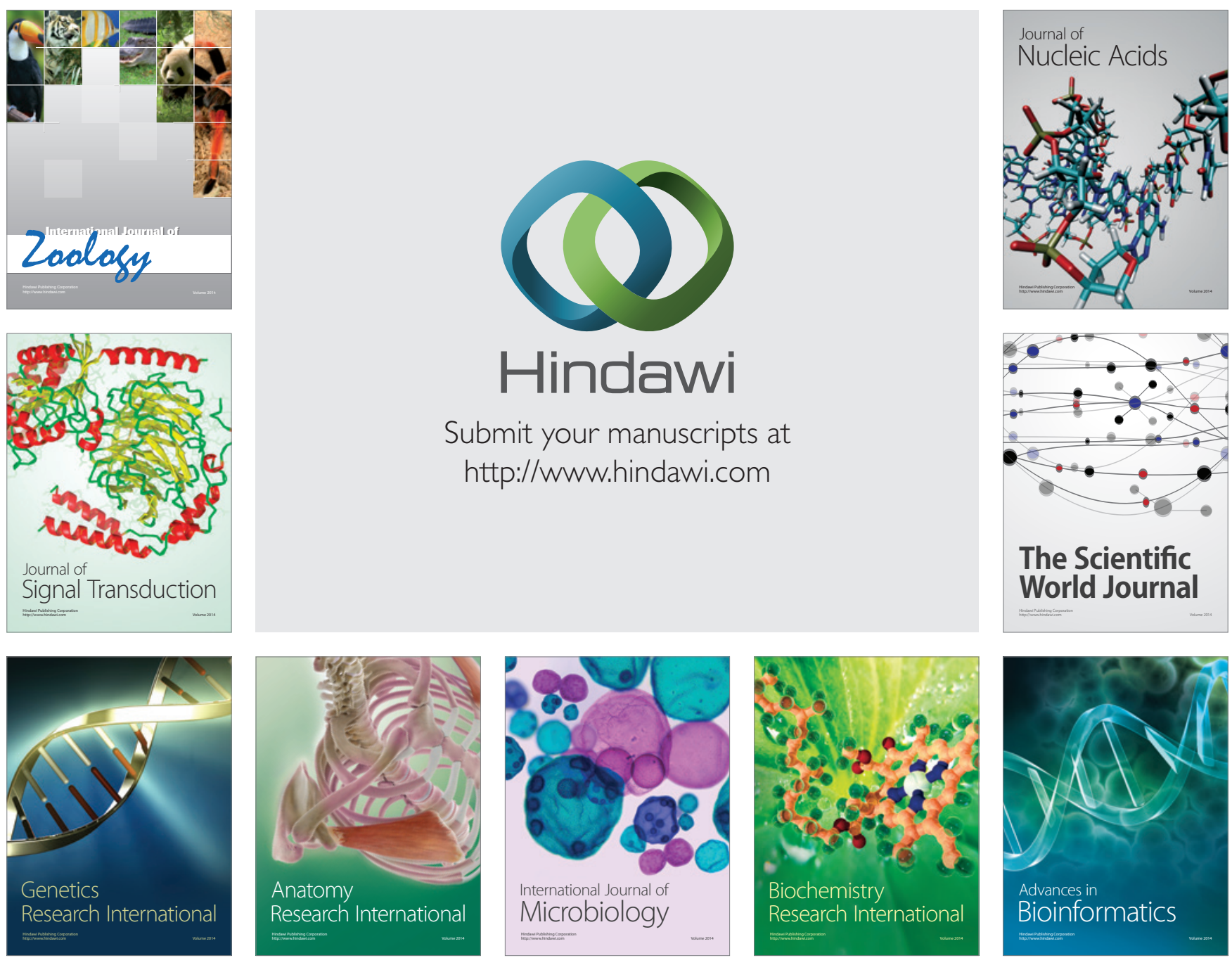

The Scientific World Journal
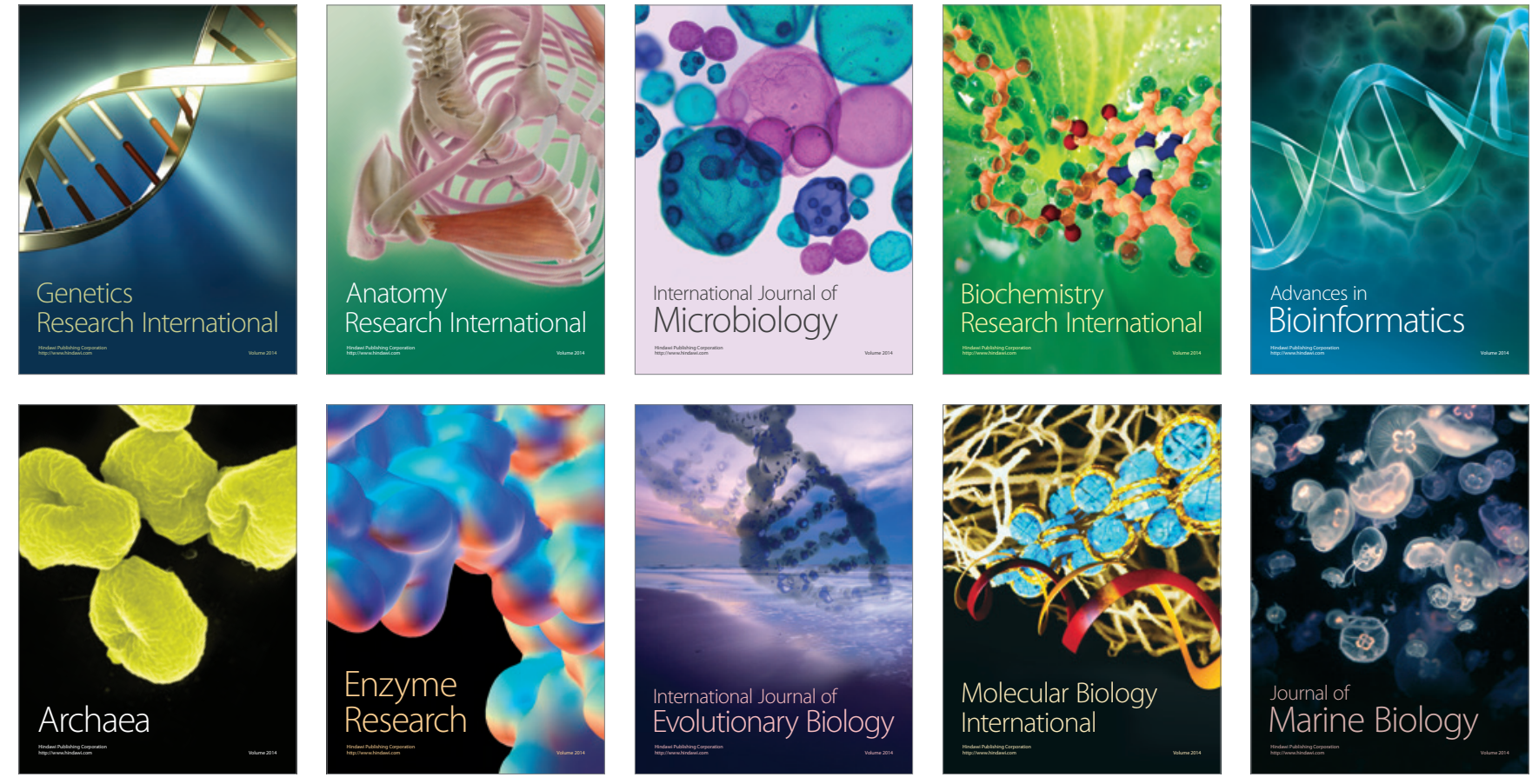